\title{
Doppler velocimetry in dichorionic twin pregnancies and its correlation with various fetal outcome
}

\author{
Netam S.S ${ }^{1}$, Kumar $S^{2}$, Fani $\mathbf{J}^{3}$, Nagaria $T^{4}$, Patre $V^{5}, \operatorname{Singh} \mathbf{R}^{6}$, Jain $V^{7}$ \\ ${ }^{1}$ Dr. Satyabhuwan Singh Netam, Professor, Dept. of Radiodiagnosis, ${ }^{2}$ Dr. Sanjay Kumar, Associate Professor, \\ Department of Radiodiagnosis, ${ }^{3}$ Dr. Jamila Fani, PG student, Department of Radiodiagnosis, ${ }^{4}$ Dr.Tripti Nagaria, \\ Professor, Department of Radiodiagnosis, ${ }^{5}$ Dr. Vivek Patre, Professor, Department of Radiodiagnosis, \\ ${ }^{6}$ Dr. Rajesh Singh, Associate Professor, Department of Radiodiagnosis, ${ }^{7}$ Dr. Vishal Jain, Assistant Professor, \\ Department of Radiodiagnosis, all authors are attached with Pt J N M Medical College Raipur, Chhattisgarh, \\ India.
}

Address for Correspondence: Dr S.B.S Netam, D-20, Avanivihar, Daldalseoni Road, Mova, Raipur, CG, India. E mail: sbsnetam@yahoo.com

\begin{abstract}
Aim: This study was to evaluate the applicability of Doppler velocimetry to determine its correlation with fetal outcome in dichorionic twin pregnancies. Material and methods: Doppler examination of the umbilical artery (UA) and middle cerebral artery (MCA) was performed in 57 twin pairs. Abnormal values of the umbilical artery pulsatility index (PI), umbilical artery Resistive index (RI) were above the 95th percentile and below 5th percentile for the Middle cerebral artery pulsatility index (MCA PI) and Middle cerebral artery resistivity index (MCA RI) for gestational week. The difference of UA PI $\geq 0.5$ in twin pairs was considered abnormal. Results: 33 subjects had a fetal discordance of greater than $15 \%$. Birth weight was found to be significantly lower in subjects with Umbilical artery PI greater than $95^{\text {th }}$ percentile for gestational age $(\mathrm{p}=0.014)$. Abnormal MCA RI $(\mathrm{P}=0.018)$ and Umbilical artery $\mathrm{RI}$ values above $95^{\text {th }}$ percentile was significantly associated with increased risk of IUGR (intra uterine growth restriction) $(\mathrm{P}=0.036)$ and NICU (Neonatal intensive care unit) admission $(\mathrm{P}=0.005)$. Increased Umbilical artery PI values above $95^{\text {th }}$ percentile was significantly associated with IUGR $(\mathrm{P}=0.003)$. Increased Umbilical Artery systolic/diastolic ratio above $95^{\text {th }}$ percentile was significantly associated with IUGR ( $\mathrm{P}=0.002)$, NICU admission $(\mathrm{P}=0.026)$ and still birth $(\mathrm{P}=0.026)$. Abnormal cerebra-umbilical ratio $(<1.08)$ was significantly associated with IUGR $(\mathrm{P}=0.001)$ and still birth $(\mathrm{P}=0.025)$. Difference in pulsatility index of umbilical artery of both fetus $(\mathrm{P} 1-\mathrm{P} 2>0.5)$ was significantly correlated with increased degree of birth weight discordance of the twins, IUGR $(\mathrm{P}=0.001)$ and still birth $(\mathrm{P}=0.001)$. Conclusion: Abnormal Doppler values in discordant twin fetus are more likely to be associated with abnormal fetal outcome.
\end{abstract}

Keywords: Color Doppler sonography, Dichorionic twin pregnancy, Doppler velocimetry, Fetal outcome

\section{Introduction}

Twins account for $3.2 \%$ of all live births [1] and $94 \%$ of all multiple births [2] and most twin gestations are of dichorionic type. Infant mortality of twins is five times greater that for singletons (37 vs. 7 per 1000 live births) [3]. Twins account for $12 \%$ to $15 \%$ of neonatal deaths [4]. Prematurity and intrauterine growth restriction (IUGR) are the main issues that increase neonatal morbidity and mortality in multiple gestations. Abnormal fetal

Manuscript received: $5^{\text {th }}$ July 2017

Reviewed: $15^{\text {th }}$ July 2017

Author Corrected: $24^{\text {th }}$ July 2017

Accepted for Publication: $31^{\text {st }}$ July 2017 growth is defined in two ways: (1) the estimated fetal weight is below the $10^{\text {th }}$ centile on a singleton curve; or (2) there is a $15 \%$ or more discordance in estimated weight between twins.

Birth weight discordance complicates more than $15 \%$ of twin pregnancies [5]. There is a higher rate of Intra uterine growth restriction in twins compared to singletons, probably caused by uteroplacental insufficiency resulting from increased metabolic demand or an abnormality involving placental implantation [6]. The neonatal mortality 
rate increases with increasing growth discordancy. Fetal hypoxia induces redistribution in the fetal circulatory system by reducing vascular resistance at the level of the brain and an increased resistance in peripheral vessels which manifests as absence and reversal of diastolic flow in umbilical arteries [7].

Cerebral circulation is regulated by several metabolic, neurogenic, and chemical factors. Brain vasculature has the ability of autoregulation thus blood flow to brain increases in initial stages of hypoxia while during the time prior to intrauterine death, loss of adaptation mechanisms and reconstruction of the vascular bed occur resulting in normal MCA values [7].

\section{Aim}

The aim of the study was to evaluate the usefulness of color Doppler in dichorionic twin pregnancies and to find its correlation with abnormal fetal outcome.

\section{Material and Methods}

study design: Observational longitudinal analytical study, sample size: 57 twin pregnancies, place of study: Department of Radiodiagnosis, Pt. JNM Medical college, Raipur (C.G), period of study: Feb 2015 to August 2016 (20 months) inclusion criteria: All antenatal patients between 17 to 42 years of age with dichorionic type of twin pregnancies referred to the department of radiodiagnosis, Dr. Bhimrao Ambedkar hospital, Raipur.

Exclusion criteria: 1. Patient unwilling to take part in study, 2. Patients with monochorionic type of twin pregnancy, 3. ANC patients with triplets and quadruplets, 4. Twin with only one viable fetus, 5. Patients with pre-eclampsia. Equipment used: GE Voluson S8 Ultrasound machine having curvilinear probe $(4 \mathrm{hz})$ and linear probe $(9 \mathrm{~Hz})$ with option of pulse wave and color Doppler.

Growth discrepancy was defined as the intertwine birth weight difference expressed as a percentage (\%) of the birth weight of the larger twin of $15 \%$ or more. Doppler examination was performed once or repeatedly.

The last result before the delivery was included into the analysis. The gestational age was determined on the basis of the first day of the last menstrual period and confirmed by the first trimester ultrasound as well as by the date of the first fetal movements. All patients gave their informed consent.

During the examination, the patients were lying in the left lateral recumbent position to avoid hemodynamic changes associated with the compression of the inferior vena cava.Time of the examination did not exceed 15-30 min. The test was performed in the absence of fetal movements and breathing activity.

Doppler examination of the blood flow in the Umbilical artery (UA) and Middle cerebral artery (MCA) was performed in all 114 fetuses. Pulsatility index (PI), Resistive index (RI) values in the umbilical artery (UA PI) above the $95^{\text {th }}$ percentile for given gestational age and the intertwine Umbilical artery pulsatility index (UA PI) difference of $\geq 0.5$ were considered abnormal.

Similarly, blood flow in the Middle cerebral artery was also studied. The Pulsatility index and Resistive Index values below the $5^{\text {th }}$ percentile for given gestational week were considered abnormal. Fetal blood flow centralization, also known as the brain sparing effect, was defined on the basis of the cerebro-umbilical ratio $(\mathrm{C} / \mathrm{U})$, which is $\mathrm{MCA}$ PI/UA PI quotient. The value of $<1.08$ was considered abnormal. Sequentially, Doppler results were compared with selected parameters that characterize the course of pregnancy and fetal outcome.

The analyzed parameters included: maternal age, obstetric history, family history of twins, history of Assisted reproductive technique used, gestational age at delivery, degree of discordance, prematurity, Small for gestational age, fetal birth weight taken within 6 hours of delivery, history of admission to neonatal intensive care unit, and early neonatal death.

Data was expressed as percentage and mean \pm S.D. Kolmogorove-Smirnove analysis was performed for checking linearity of the data. Fischer's exact test or Chi square test was used to analyze the significance of difference between frequency distribution of the data. Student's $t$ test was used to compare between two categorical variables. $\mathrm{P}$ value $<0.05$ was considered as statistically significant. 


\section{Result}

Out of the total 57 pregnancies 33 subjects had a fetal discordance of greater than $15 \%$, out of which 27 twin pairs had discordance in growth between 15-25\%, 3 twin pairs had discordance ranging between $26-35 \%$ and 3 twin pairs had discordance of greater than $35 \%$. In our study $36.84 \%$ of mothers were primi-gravida and $63.16 \%$ of the mothers were multigravida and $7.02 \%$ of mothers had family history of twins. Only $0.9 \%$ of patients gave history of conception by Assisted Reproductive Technique (ART).

Out of the total study subjects $43 \%$ had Middle Cerebral Artery Resistive Index of $<5^{\text {th }}$ percentile for gestational age, $38 \%$ had Middle cerebral artery Pulsatility Index $<5^{\text {th }}$ percentile for gestational age and $39.5 \%$ had Middle cerebral artery systolic/diastolic M9CA S/D) $<5^{\text {th }}$ percentile for the gestational age. $2.6 \%$ of the subjects had Umbilical artery RI $>95^{\text {th }}$ percentile, $5.26 \%$ had Umbilical artery PI $>95^{\text {th }}$ percentile and $27 \%$ had Umbilical artery $\mathrm{S} / \mathrm{D}>95^{\text {th }}$ percentile. Brain sparing effect which is cerebro-umbilical ratio less than 1.08 is seen in $28.9 \%$ of fetus. The difference of Pulsatility Index of umbilical artery of both fetus (P1-P2) greater than 0.5 was present in $14 \%$ of the subjects. In our study $43 \%$ of subjects delivered between $34-37$ weeks while $28 \%$ of delivered after 37 weeks and $28 \%$ delivered before 34 weeks of gestation. Out of the total infants $61.4 \%$ had preterm delivery. Out of the total twin pregnancies $53.5 \%$ delivered by lower segment caesarian section (LSCS) and $46.4 \%$ through normal vaginal delivery. In the present study $69 \%$ of fetus had birth weight between $1500-2500$ grams followed by $16 \%$ between $1000-1500$ grams.

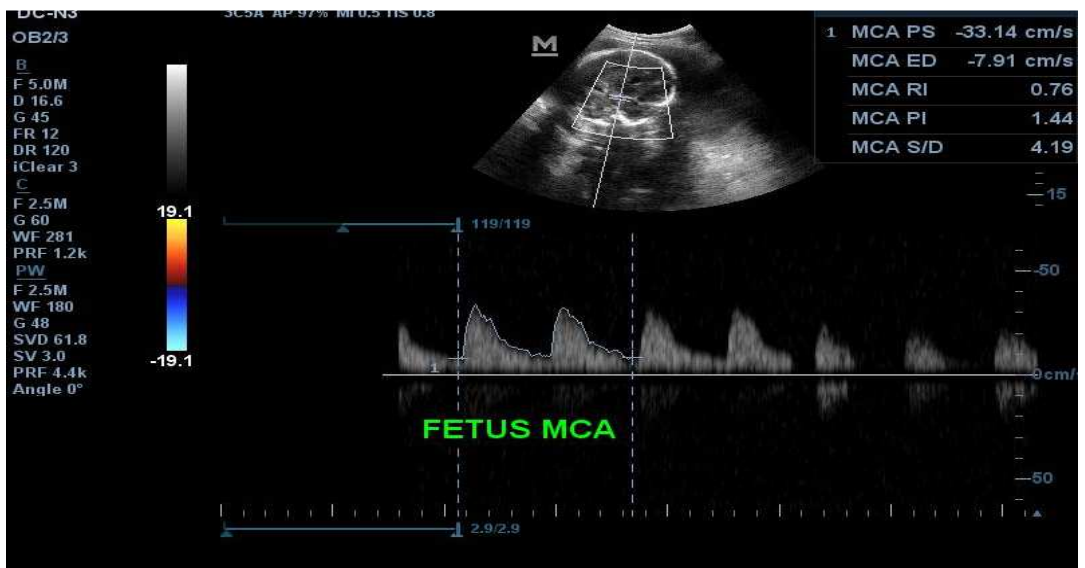

Fig-1: Color Doppler Middle cerebral artery of fetus A of a 29 year old female G3P1L1 came to out patient department at 29 weeks of gestation, showing resistive index below $5^{\text {th }}$ percentile for gestational age.

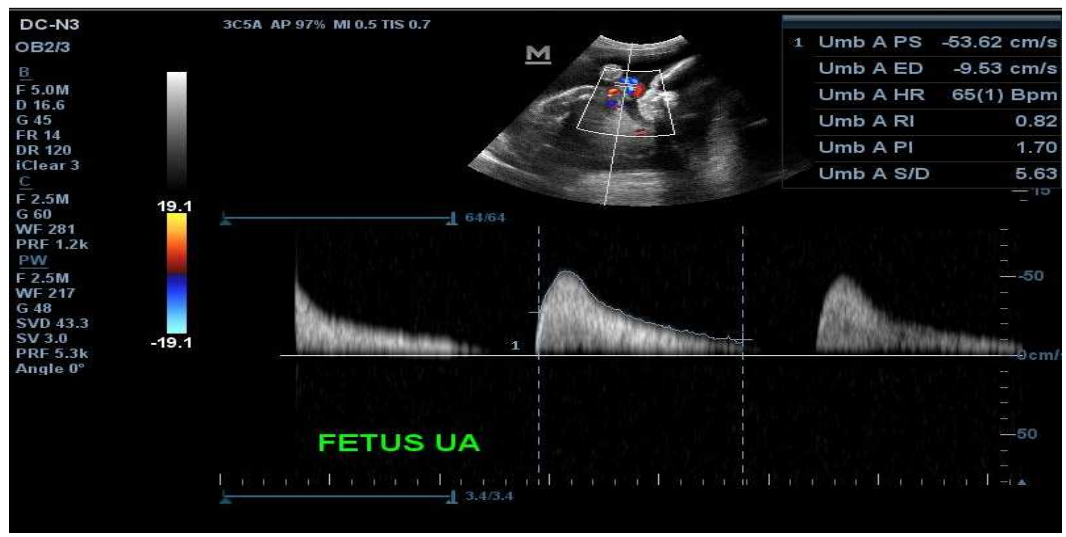

Fig-2: Color Doppler of Umbilical artery of fetus A showing Pulsatility index \& Systolic to diastolic ratio above $95^{\text {th }}$ percentile for gestational age with decreased diastolic flow. Cerebro-umbilical ratio of fetus A was found to be 0.66 suggestive of brain sparing effect in fetus A. These finding correlated well with Intra Uterine Growth Restriction and admission to neonatal intensive care unit of fetus A, Also increased umbilical artery pulsatility index correlated with low birth weight of 1800 grams. 


\section{Original Research Article}

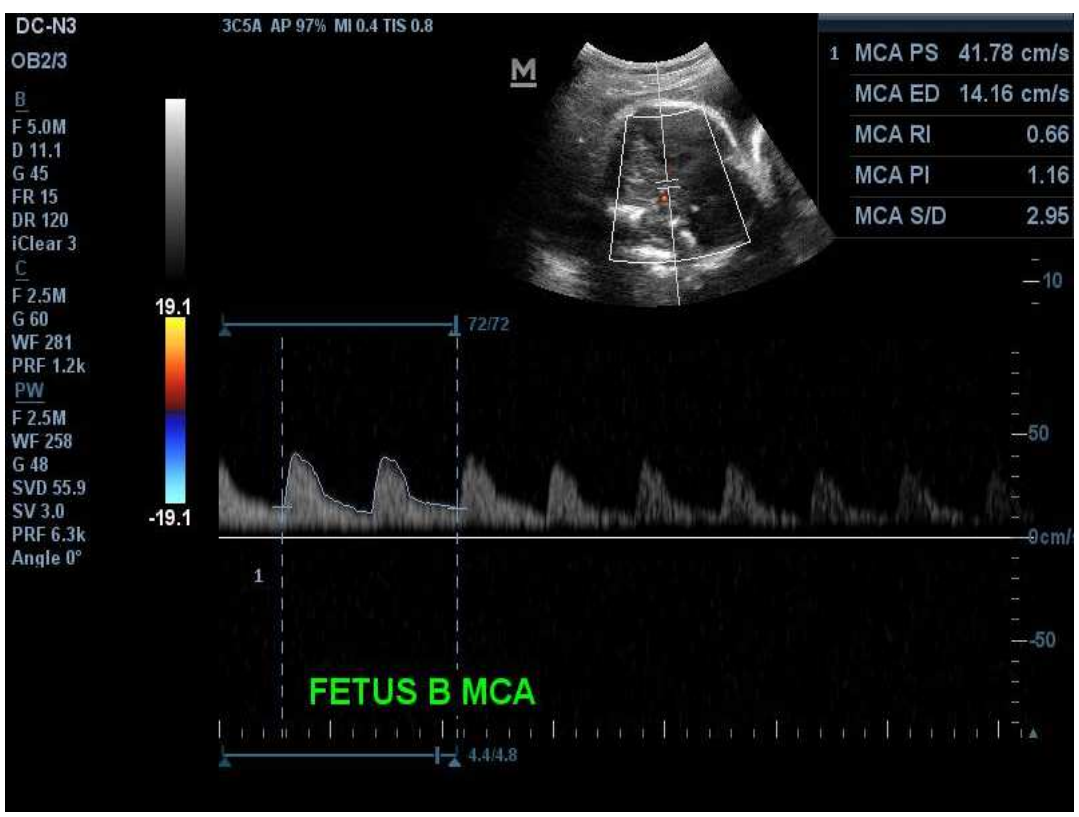

Fig-3: Color doppler of Middle cerebral artery of fetus B showing normal Middle cerebral artery values and waveform.

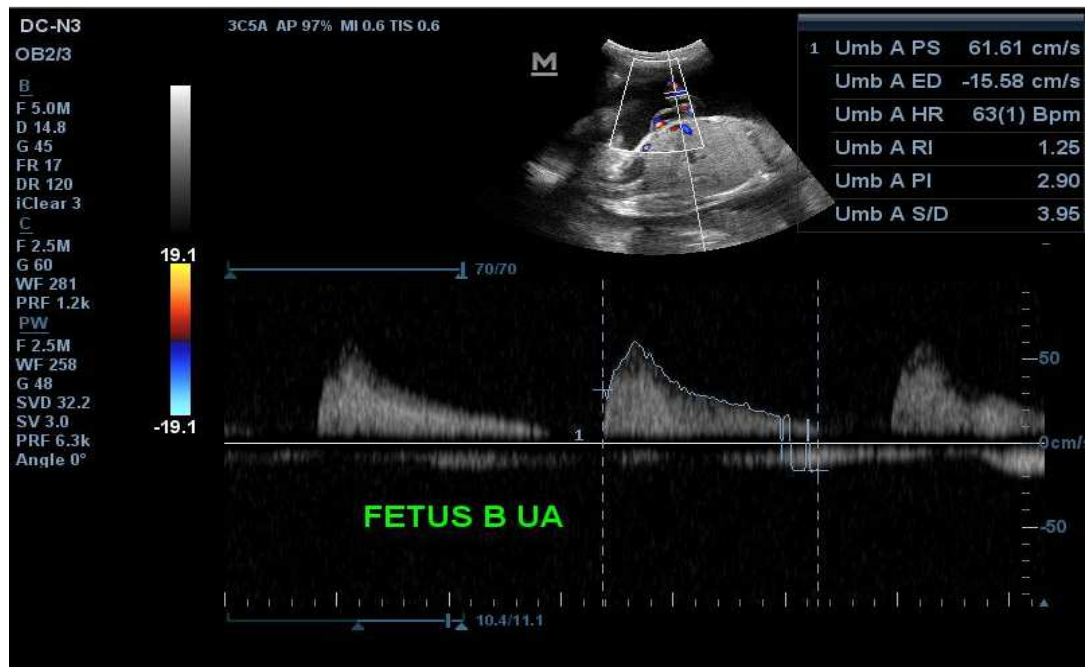

Fig-4: Color Doppler of Umbilical artery of Fetus B showing systolic to diastolic ratio above $95^{\text {th }}$ percentile for gestational age with normal Pulsatility index \& Resistive index. Abnormal Systolic to diastolic ratio of umbilical artery correlated well with Intra Uterine Growth Restriction \& still birth. Difference of pulsatility index of both fetus was found to be $(\mathrm{P} 1-\mathrm{P} 2)=0.57$. Patient delivered preterm at 34 weeks of gestation through lower segment caesarian section. Birth weight discordance at the time of delivery was found to be $35 \%$ that correlated well with (P1-P2>0.5).

On association studies, birth weight was found to be significantly lower in subjects with Umbilical artery PI greater than $95^{\text {th }}$ percentile for gestational age $(\mathrm{p}=0.014)$. Abnormal Middle cerebral artery resistive index (MCA RI) ( $\mathrm{P}=0.018)$ and Middle cerebral artery pulsatility index (MCA PI) $(\mathrm{P}<0.001)$ values were found to be significantly associated with increased risk of prematurity. Increased Umbilical artery Resistive Index values above $95^{\text {th }}$ percentile was significantly associated with increased risk of Intra Uterine Growth Restriction $(\mathrm{P}=0.036)$ and increased risk of neonatal intensive care unit admission $(\mathrm{P}=0.005)$. Increased Umbilical artery PI values above $95^{\text {th }}$ percentile was significantly associated with increased risk of Intra Uterine Growth Restriction $\left(\mathrm{P}=0.003\right.$ ) (Fig 2). Increased Umbilical Artery S/D ratio above $95^{\text {th }}$ percentile was significantly associated with increased risk of Intra Uterine Growth Restriction $(\mathrm{P}=0.002)$, increased risk of neonatal intensive care unit admission $(\mathrm{P}=0.026)$ and increased risk of still birth $(\mathrm{P}=0.026)$ (Fig 2, Fig 4). Abnormal cerebro-umbilical ratio 
$(<1.08)$ was significantly associated with increased risk of Intra Uterine Growth Restriction $(\mathrm{P}=0.001)$ and increased risk of still birth $(\mathrm{P}=0.025)$. Birth weight was found to be significantly higher in subjects with higher cerebro-umbilical ratio (normal $\mathrm{C} / \mathrm{U}$ of $>1.08$ ). Difference of pulsatility index of umbilical artery of both fetus $(\mathrm{P} 1-\mathrm{P} 2>0.5)$ had significant correlation with increased degree of birth weight discordance between the twins, IUGR $(\mathrm{P}=0.001)$ and increased rate of still birth $(\mathrm{P}=0.001)$ (Fig 4).

No association was seen between abnormal umbilical artery pulsatility index and gestational age. No association was seen between difference in pulsatility index of umbilical artery of both fetus (P1-P2) with gestational age and birth weight. No association was seen between abnormal MCA S/D value and various fetal parameters.

Table showing positive association of various Doppler parameters and its correlation with various fetal outcome parameters was assessed using Fischer's exact test/ Chi square test and their p values:

\begin{tabular}{|c|c|c|}
\hline Color doppler parameter & Fetal outcome parameter & $\mathbf{P}$ values \\
\hline Increased umbilical artery Pulsatility index(UA PI) & Low birth weight & 0.014 \\
\hline Difference of PI of umbilical artery of both fetus (P1-P2) $>0.5$ & $\begin{array}{l}\text { Discordance in birth weight of } \\
\text { greater than }>15 \%\end{array}$ & 0.001 \\
\hline Decreased Middle cerebral artery pulsatility index( MCA PI) & Prematurity & $<0.001$ \\
\hline Decreased middle cerebral artery resistive index (MCA RI) & Prematurity & 0.018 \\
\hline Increased umbilical artery resistive index(UA RI) & Intra uterine growth restriction & 0.036 \\
\hline Increased umbilical artery resistive index( UA RI) & $\begin{array}{l}\text { Neonatal intensive care unit } \\
\text { admission }\end{array}$ & 0.005 \\
\hline Increased umbilical artery pulsatility index (UAPI) & Intra uterine growth restriction & 0.003 \\
\hline Increased umbilical artery systolic to diastolic ratio(UA S/D) & Still birth & 0.002 \\
\hline Increased umbilical artery systolic to diastolic ratio(UA S/D) & $\begin{array}{l}\text { Neonatal intensive care unit } \\
\text { admission }\end{array}$ & $<0.0001$ \\
\hline Cerebro-umbilical ratio $(\mathrm{C} / \mathrm{U})<1.08$ & Intra uterine growth restriction & $<0.0001$ \\
\hline Cerebro-umbilical ratio $(\mathrm{C} / \mathrm{U})<1.08$ & Low birth weight & 0.026 \\
\hline Cerebro-umbilical ratio $(\mathrm{C} / \mathrm{U})<1.08$ & $\begin{array}{l}\text { Neonatal intensive care unit } \\
\text { admission }\end{array}$ & 0.025 \\
\hline $\begin{array}{l}\text { Difference in pulsatility index of umbilical artery of both fetus } \\
\qquad(\mathrm{P} 1-\mathrm{P} 2)>0.5\end{array}$ & Intra uterine growth restriction & $<0.0001$ \\
\hline
\end{tabular}

\section{Discussion}

Two important complications occurring in dichorionic twins are discordant fetal growth and prematurity. Abnormal fetal growth is defined in two ways: (1) the estimated fetal weight is below the 10 th centile on a singleton curve; or (2) there is a $15 \%$ or more discordance in estimated weight between twins (Divon \& Weiner) [8].Birth weight discordance complicates more than $15 \%$ of twin pregnancies [9]. Doppler waveforms, fetal biometry and estimated fetal weight are all helpful in assessing for discordance in the second and third trimesters.

The aim of this study was to evaluate the applicability of color doppler ultrasonography in predicting the course of pregnancy and fetal outcome in twin pregnancies complicated by growth discordance.
In our study, out of total deliveries, $61.4 \%$ were preterm which is very similar to the study conducted by MD Michael O Gardner et al[10] in which $54 \%$ of twins were preterm compared with 9.6\% among singletons. Chae Min Lee et al [11] in his study found that the mean duration of pregnancy for twin gestations was 29.5 weeks, and deliveries at less than 36 weeks were $76.1 \%$.

Difference of pulsatility index of umbilical artery of both fetus (P1-P2) $>0.5$ correlated significantly $(\mathrm{p}=0.001)$ with discordance between the twin pairs of $15-25 \%$, Intra uterine growth restriction (that is birth weight below $10^{\text {th }}$ percentile of the fetus) with $(\mathrm{p}=0.001)$ and total number of still birth $(\mathrm{p}=0.001)$ which is similar to the study conducted by Mariola Ropacka-Lesiak et al [9] in which intertwine PI difference of 0.5 and 
more correlated significantly with lower gestational age at delivery, intertwine growth discordance of $35 \%$ or more, lower birth weight, and abnormal fetal outcome.

Miller et al [12] analyzed twin gestations with growth discordance of at least $20 \%$. They found that discordant growth alone is not an indication for preterm birth which is similar to our study in which no association was noted between discordant growth and preterm delivery.

In our study, abnormal umbilical artery indices Umbilical Artery Resistive Index $>95$ percentile correlated significantly ( $p=0.036$ ) with percentage of fetus below $10^{\text {th }}$ percentile and rate of admission to neonatal intensive care unit $(\mathrm{p}=0.005)$. Umbilical Artery Pulsatility Index $>95$ percentile correlated significantly with low birth weight $(\mathrm{P}=0.014)$ and Intra uterine growth restriction $(\mathrm{P}=0.003)$. These results were similar to the study conducted by Mariola Ropacka-Lesiak et al[7] who reported that abnormal Umbilical artery Pulsatility Index correlated significantly with lower gestational age at delivery, intertwine growth discordance of $35 \%$ or more, lower birth weight, and abnormal fetal outcome.

In present study, Umbilical Artery S/D ratio of $>95$ percentile correlated significantly with intra uterine growth restriction $(\mathrm{p}=0.002)$, Rate of admission to neonatal intensive care unit $(\mathrm{p}=0.026)$ and with still birth $(p<0.001)$. This is similar to the study conducted by B. J. Trudingeret al [13] studied the correlation between abnormal S/D ratio of Umbilical artery inmonochorionic and dichorionic twins. They found that the abnormal S/D ratio of Umbilical Artery of smaller fetus correlated with Small for gestational age fetus at the time of delivery. Similarly study by Wang Z et al [14] also confirms that $S / D$ ratio of both umbilical artery and uterine artery in Intra uterine growth restricted fetus were significantly higher than those in normal fetus.

In the present study, abnormal values of Middle cerebral artery resistive index and Pulsatility index below $5^{\text {th }}$ percentile for gestational age correlated significantly with occurrence of prematurity $(\mathrm{P}$ value for MCA RI=0.018 and $\mathrm{P}$ value for MCA PI $<0.0001$ ) while no significant correlation was seen between Middle cerebral artery systolic to diastolic ratio (MCA S/D) and various fetal parameters. Present study result contrasts to the study result of Mariola Ropacka-Lesiak [7] et al who concluded that there were no statistically significant differences occur in majority of parameters that characterize the neonatal outcome between the groups with normal and abnormal Middle cerebral artery pulsatility index (MCA PI). The results of the present study is similar to the work of other authors like Mari G et al [15]who suggested that small for gestational age fetus with a normal middle cerebral artery Pulsatility Index was at lower risk of abnormal fetal outcome than the fetus with abnormal Pulsatility index values and Joern et al [16] who assessed the predictive value of a combined analysis of blood flow in the aorta, umbilical artery, and Middle cerebral artery in predicting the birth weight of small for gestational age infant.

Brain sparing effect in twins is determined in our study by calculating cerebro-umbilical $(\mathrm{C} / \mathrm{U})$ ratio which is the ratio of Pulsatility Index of Middle cerebral artery to the Pulsatility index of umbilical artery and the value below 1.08 is considered abnormal. $28.9 \%$ of the total fetus had cerebroumbilical $(\mathrm{C} / \mathrm{U})$ ratio below 1.08. Significant correlation was observed between decreased cerebro-umbilical $(\mathrm{C} / \mathrm{U})$ ratio and Intra Uterine Growth Restriction ( $\mathrm{P}$ value $=0.026$ ) and also significant correlation was observed between abnormal cerebro-umbilical $(\mathrm{C} / \mathrm{U})$ ratio with Neonatal intensive care unit admission $(\mathrm{P}=0.025)$. Higher birth weight was observed in the subjects with cerebro-umbilical $(\mathrm{C} / \mathrm{U})$ ratio $>1.08$.These findings were similar to the study done by BahadoSingh et al[17], who showed a higher prognostic value of this phenomenon in comparison to blood flow assessment in the umbilical artery in predicting an unfavorable prognosis for the fetus with growth restriction. Similarly, Arias et al [18] found that the occurrence of centralization of fetal circulation in a single pregnancy is associated with high risk of growth restriction and neonatal morbidity. Similarly, in study by Ropacka-Lesiak et al [7] the brain-sparing phenomenon was observed in $27.4 \%$ of twins with discordant growth and those twins were at risk of premature delivery, mean weight was significantly lower $(1,460 \mathrm{~g}$ vs.1,980 g), and there was higher percentage of small for gestational age infants (53.9\% vs. 46.2\%) and adverse fetal outcome compared to the group 
without the brain-sparing effect. Similarly, Gaziano et al [19] found that the brain-sparing effect has the highest predictive value in relation to fetal growth disturbance like small for gestational age, abnormal fetal outcome, and the length of hospitalization compared to blood flow monitoring in only one vessel.

\section{Conclusion}

Color Doppler play an important role, if there is discordance in birth weight of greater than $15 \%$ is observed in $2^{\text {nd }}$ or $3^{\text {rd }}$ trimester of pregnancy and it should be recommended for blood flow changes.

Abnormal color doppler values in discordant twin fetus is more likely to be associated with abnormal fetal outcome and absence of abnormal indices and their ratios have high likelihood of normal perinatal outcome in twin pregnancies.

\section{Funding: Nil, Conflict of interest: None Permission of IRB: Yes}

\section{References}

1. Martin JA, Hamilton BE, Sutton PD, Ventura SJ, Menacker F, Kirmeyer S, Munson ML; Centers for Disease Control and Prevention National Center for Health Statistics National Vital Statistics System. Births: final data for 2005. Natl Vital Stat Rep. 2007 Dec 5;56(6):1-103.

2. Luke B, Martin JA. The rise in multiple births in the United States: who, what, when, where, and why. ClinObstetGynecol 2004;47:118-133.

3. Misra DP, Ananth CV. Infant mortality among singletons and twins in the United States during 2 decades: effects of maternal age. Pediatrics. 2002 Dec;110(6):1163-8.

4. Taylor MJ. The management of multiple pregnancy. Early Hum Dev. 2006 Jun; 82 (6): 36570. Epub 2006 May 4.

5. Rodis JF, Vintzileos AM, Campbell WA, Nochimson DJ. Intrauterine fetal growth in discordant twin gestations. J Ultrasound Med. 1990 Aug; 9(8):443-8.

6. Mordel N, Benshushan A, Zajicek G, Laufer N, Schenker JG, Sadovsky E. Discordancy in triplets. Am J Perinatol. 1993 May;10(3):224-5.
7. Twin Research and Human Genetics Volume 15 Number 6 pp. 781-787 C _ The Authors 2012 Flow Changes in Dichorionic Twins With Growth Discordance Mariola Ropacka- Lesiak, Grzegorz Bre, borowicz, and Anna Dera.

8. Divon MY, Weiner Z. Ultrasound in twin pregnancy. Semin Perinatol. 1995 Oct;19(5): 404-12.

9. Alam Machado Rde C, Brizot Mde L, Liao AW, Krebs VL, Zugaib M. Early neonatal morbidity and mortality in growth- discordant twins. Acta Obstet Gynecol Scand. 2009; 88 (2): 167-71. doi: $\quad 10 . \quad 1080 / \quad 000 \quad 163 \quad 408 \quad 026 \quad 49$ 808.

10. Michael O, Gardner, Robert L. Goldenberg, et al. The origin and outcome of preterm twin pregnancies. Obstetrics \& Gynecology ,Volume 85, Issue 4, April 1995, Pages 553-557.

11. Lee CM, Yang SH, Lee SP, Hwang BC, Kim SY. Clinical factors affecting the timing of delivery in twin pregnancies. Obstet Gynecol Sci. 2014 Nov;57(6):436-41. doi: 10.5468/ogs.2014.57.6.436. Epub 2014 Nov 20.

12. Miller J, Chauhan SP, Abuhamad AZ. Discordant twins: diagnosis, evaluation and management. Am J Obstet Gynecol. 2012 Jan; 206 (1): 10-20. doi: 10.1016/j.ajog.2011.06.075. Epub 2011 Jun 25.

13. Fetal umbilical artery flow velocity-time waveforms in twin pregnancies-warwick $b$. giles,brian j. trudinger,colleen m. cook,bjog: an international journal of obstetrics \& gynaecology Volume 92, Issue 5, Version of Record online: 23 AUG 2005.

14. Wang KG, Chen CP, Yang JM, Su TH. Impact of reverse end-diastolic flow velocity in umbilical artery on pregnancy outcome after the 28th gestational week. Acta Obstet Gynecol Scand. 1998 May;77(5):527-31.

15. Mari G, Deter RL. Middle cerebral artery flow velocity waveforms in normal and small forgestational-age fetuses. Middle cerebral artery velocimetry: Am J Obstet and Gynecol, 1992; 166 (4): 1262-1270. 
16. Joern, H., Schroeder,W., Sassen, R., \& Rath, W. (1997). Predictive value of a single CTG, ultrasound and Doppler examination to diagnose acute and chronic placental insufficiency in multiple pregnancies. Journal of Perinatal Medicine, 25,325-332.

17. Bahado-Singh, R. O., Kovanci, E et al. The Doppler cerebroplacental ratio and perinatal outcome in intrauterine growth restriction. American Journal of Obstetrics and Gynecology 1999; 180,750-756.
18. Arias, F. Accuracy of the middle-cerebral-toumbilical artery resistance index ratio in the prediction of neonatal outcome in patients at high risk for fetal and neonatal complications. American Journal of Obstetrics and Gynecology 194;171: 1541-154.

19. Gaziano, EP, Gaziano C., Terrell, C. A., \& Hoekstra, R. E. The cerebroplacental Doppler ratio and neonatal outcome in diamnionic monochorionic and dichorionic twins. Journal of Maternal Fetal Medicine, 2001;10: 371-375.

\section{How to cite this article?}

Netam S.S, Kumar S, Fani J, Nagaria T, Patre V, Singh R, Jain V. Doppler velocimetry in dichorionic twin pregnancies and its correlation with various fetal outcome. Int J Med Res Rev 2017;5(07):740747.doi:10.17511/ijmrr. 2017.i07.13. 